Brit. Heart F., 1966, 28, 512.

\title{
The Right Ventricle and Pulmonary Vascular Obstruction in Bronchitis with Emphysema
}

\author{
W. R. L. JAMES \\ From the Department of Pathology, Welsh National School of Medicine, Cardiff
}

Enlargement of the right ventricle occurs in some patients with chronic bronchitis and emphysema, while the right ventricle is normal in others with similar lung changes (Leopold and Gough, 1957). If the hypertrophy of the ventricle were a response to increased work, it would be expected that either the cardiac output or the pulmonary artery pressure or both would be increased. In most patients who are not in failure the cardiac index is about normal, and there is often a slight rise in pulmonary artery pressure. A temporary further increase of pressure occurs during phases of congestive failure (Harris and Heath, 1962b). There is also evidence of a slight rise in pulmonary vascular resistance at rest, the increase becoming greater on exercise (Blount, 1959). In some patients with cor pulmonale the pulmonary artery pressure does not return to normal after recovery from acute infection, and in these patients obliteration of the pulmonary vascular bed may contribute to increased vascular resistance (Hugh-Jones, 1960). These observations suggest that in some cases of chronic bronchitis and emphysema there are two groups of factors tending to increase the pulmonary vascular resistance-permanent, possibly anatomical ones, and transient functional factors. The object of the present work was to assess the possible permanent anatomical factor by testing the patency of the vascular bed after death, and to consider the significance of any observed reduction in patency in relation to enlargement of the right ventricle.

\section{SuBJECTS AND METHOD}

The right lungs of 68 subjects were tested for vascular bed patency at necropsy. Of these, 15 were excluded because examination after perfusion showed that one or more of the vessels contained recent emboli, thrombi, or

Received July 23, 1965. post-mortem clot. The remaining 53 comprised lungs from normal subjects, asthmatics, and patients who had had chronic bronchitis and emphysema.

Sixteen of the lungs were from normal persons aged 20 to 78 , who had no clinical or post-mortem evidence of heart or lung disease. The causes of death were carcinoma of the alimentary canal (3), cerebral tumour (3), drowning (3), prostatic enlargement (2), fractured skull, hanging, epilepsy, aplastic anæmia, liver necrosis (one of each).

Six were from patients who had been treated for paroxysmal asthma for years before dying in status asthmaticus. There was no evidence at necropsy of any disease other than asthma. Their ages ranged from 16 to 68 . Thirty-one were obtained from patients who had been clinically diagnosed as having chronic bronchitis and emphysema. They were selected by excluding those with other coexisting lung diseases or primary heart disease revealed at necropsy. The age range was 49 to 79 . The degree of emphysema varied from slight to severe (Fig. 1). In 30, the emphysema was centrilobular in type (Leopold and Gough, 1957); in only one was it purely panacinar.

At necropsy care was taken to avoid pleural tears. It was sometimes necessary to strip the parietal pleura to avoid damage to the visceral pleura. The thoracic organs were removed en bloc, the pericardium incised, and the heart removed by cutting immediately above the pulmonary and aortic valves. The bifurcation of the pulmonary trunk being visible, the right lung was removed, ensuring that the line of section was at the origin of the right pulmonary artery. Clots were extracted from the main lung vessels, and the lung was gently squeezed from the periphery to the hilum to express smaller clots. A metal cannula, 0.5 in. (1.27 $\mathrm{cm}$.) internal diameter, was tied into the main pulmonary artery, and the lung was placed to float in a bowl of 10 per cent liquor formaldehyde with 4 per cent sodium acetate. A 1.5 litre reservoir fitted with rubber tube, 0.5 in. $(1.27 \mathrm{~cm}$.), was filled with the formol sodium acetate solution and suspended above the floating lung. The metal cannula and rubber tube were both filled with the solution and connected together while the fluid was flowing, to avoid the entry of air bubbles. The tube 


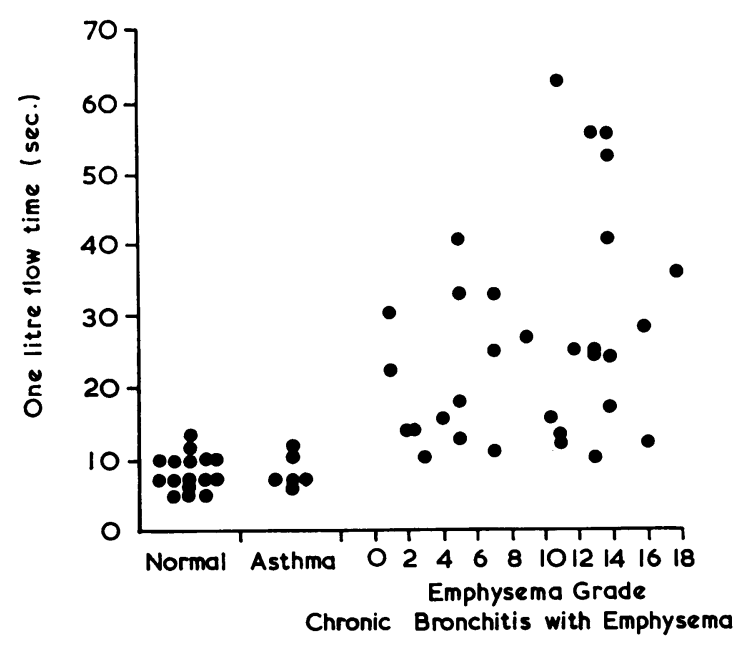

FIG. 1.-The time taken for one litre of fluid to flow through normal lungs, lungs from asthmatics, and lungs from patients who had had chronic bronchitis with emphysema.

was clipped and time allowed for the floating lung to rotate into a position in which the pulmonary artery and tube were free from torsion. Half a litre of fluid was then allowed to flow from the reservoir until the level fell to a mark indicating that one litre remained in the reservoir. A stopwatch was then used to measure the time taken for the remaining one litre to flow. This time was used as a measure of the post-mortem resistance of the pulmonary vascular bed.

The length of the rubber tube was adjusted so that it was vertical, the reservoir fluid level falling from $70 \mathrm{~cm}$. to $60 \mathrm{~cm}$. above the lung hilum while the timed litre of fluid flowed. After vascular perfusion sagittal whole lung slices were examined for the presence of recent emboli, thrombi, or clots which might invalidate the assessment of chronic obstructive changes. From the initial series of 68 lungs, 15 were excluded for this reason. One lung slice was used for preparing a whole lung section by the technique of Gough and Wentworth (1960).

The degree of anatomical emphysema was assessed from the paper-mounted whole lung section by applying the method of Heard and Izukawa (1964). This involves dividing the whole lung section into 6 areas by superimposing a marked perspex sheet. Emphysema is graded by scoring one point for each one-third of each area affected. A score of $0 / 18$ indicates no emphysema: $18 / 18$ indicates that the entire lung cut surface is involved in air-space enlargement.

The heart was emptied and weighed. The atria were removed by cutting along the atrio-ventricular sulci. The free right ventricular wall was removed by cutting through the points of maximum concavity between the right ventricular wall and the septum. The free left ventricular wall was removed similarly.

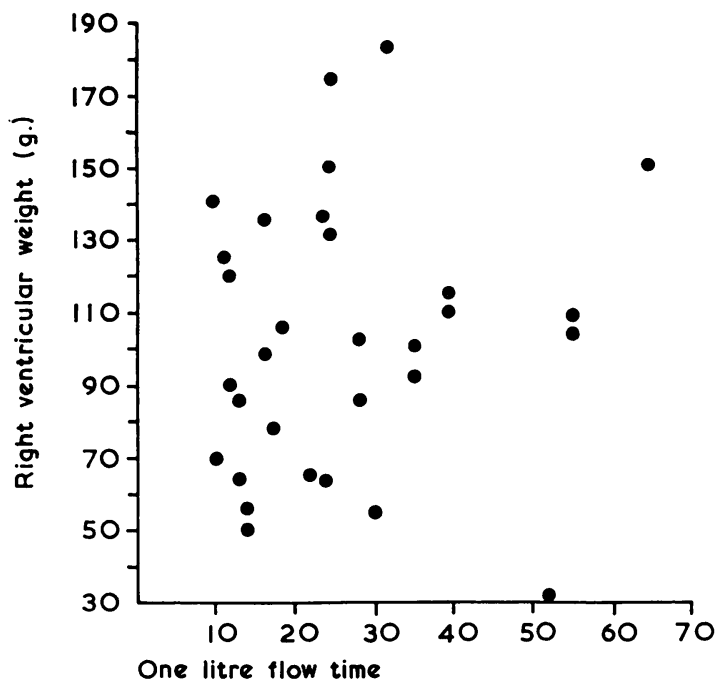

FIG. 2.-The right ventricular weights and one litre flow times in necropsy specimens from 31 patients who had had chronic bronchitis with emphysema.

This method of dissection was chosen because it is simple and rapid and it facilitates re-assembly for inspection by subsequent examiners. The free ventricular walls were weighed and the ratio (weight of right ventricle)/(weight of left ventricle) was calculated.

\section{RESULTS}

Fig. 1 shows the times taken for one litre of fluid to flow through the pulmonary vascular bed. In normal subjects the range was 5 to $13 \mathrm{sec}$., mean $8 \mathrm{sec}$. The range in the asthmatics was 6 to 12 sec., mean $8 \mathrm{sec}$. In the 31 lungs affected by chronic bronchitis and emphysema the range was 10 to $62 \mathrm{sec}$. and the mean $26 \mathrm{sec}$. Hence in this study the mean resistance in the chronic bronchitis with emphysema group was about three times the mean of the normals. However, in 9 of the 31 the rate of flow was within the normal range and in 4 of these 9 the emphysema score was over $9 / 18$. Hence, severe emphysema is compatible with a normal post-mortem pulmonary vascular resistance. An example is illustrated in Fig. 3 which shows a whole lung section from a man of 59 who had had dyspnœe, wheeze, and sputum for 15 years before his death from a bleeding duodenal ulcer (emphysema score $11 / 18$; one litre flow time, $13 \mathrm{sec}$.).

The flow times and right ventricular weights in the 31 chronic bronchitics with emphysema lungs are shown in Fig. 2. The two factors were not related. Of the 9 with normal flow times the right ventricle was hypertrophied in 5 . For example, in the lung shown in Fig. 3 the flow time 


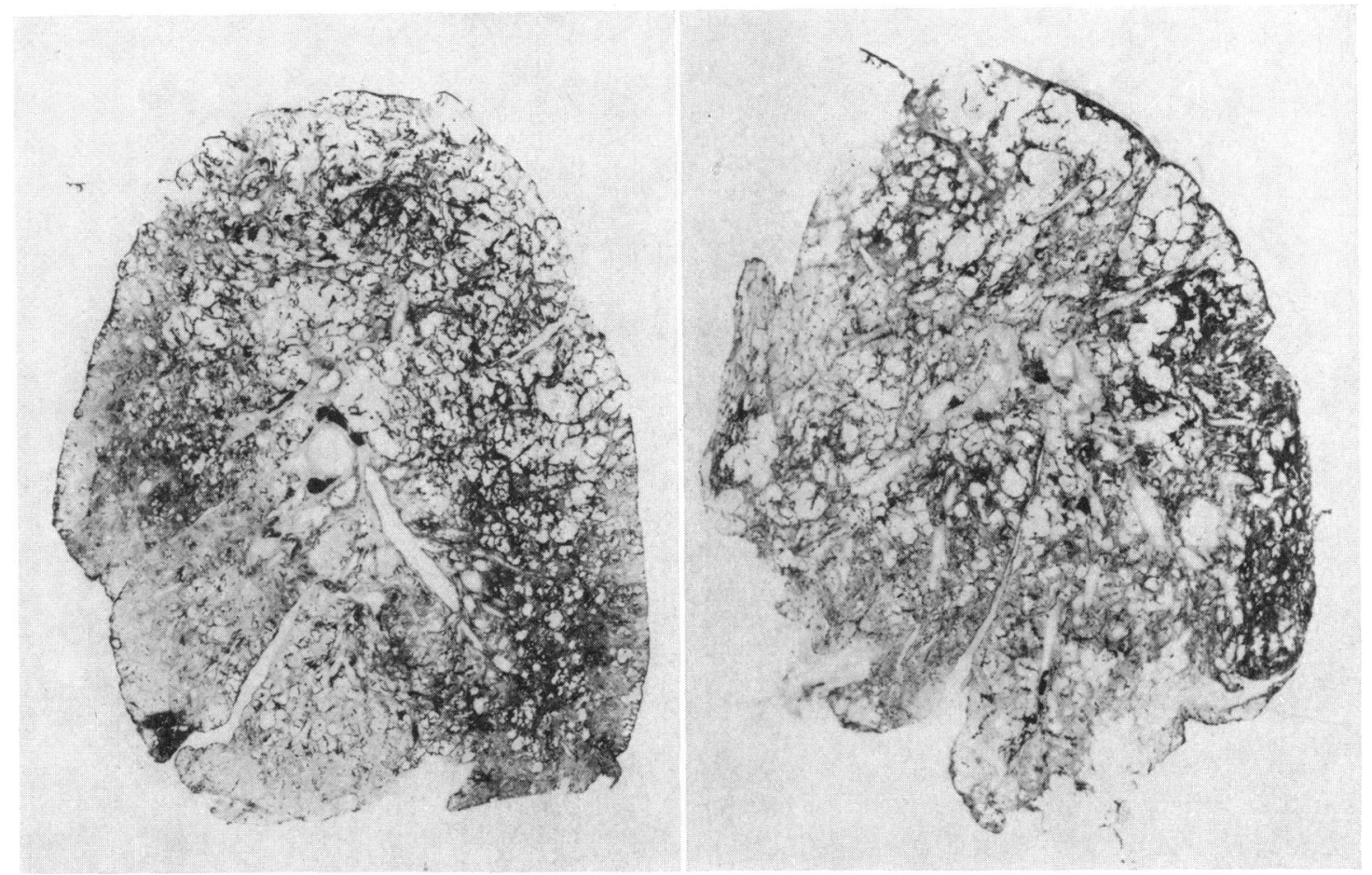

FIG. 3.-A whole lung section from a man of 59 who had had chronic bronchitis for 15 years. Severe emphysema (score 11/18). One litre flow time, $13 \mathrm{sec}$. Right ventricular weight $120 \mathrm{~g}$. Compare Fig. 4.

FIG. 4.-The right lung from a man of 70 who had had symptoms of chronic bronchitis for 17 years. Severe emphysema (score 14/18). One litre flow time $52 \mathrm{sec}$. Right ventricular weight $32 \mathrm{~g}$.

was normal $(13 \mathrm{sec}$.), but the right ventricle weighed $120 \mathrm{~g}$. compared with the upper limit of $80 \mathrm{~g}$. observed in the normal group in this study.

Of the 22 with slow flow rates, 5 had normal right ventricles. Fig. 4 illustrates such a case. A man of 70 had been an invalid due to chronic bronchitis for over 17 years before his death from ventilatory failure. The flow time was $52 \mathrm{sec}$., about 6 times the normal mean, but the weight of his free right ventricular wall was only $32 \mathrm{~g}$. The $\mathrm{RV} / \mathrm{LV}$ weight ratio was 0.53 , which is also within the normal range. These results show that normal right ventricular weight may coexist with increased post-mortem pulmonary vascular resistance, and heavy right ventricles with normal vascular bed patency.

The right ventricular weights in the normal subjects, those with asthma, and those with emphysema are shown in Fig. 5, the emphysema cases being graded according to the emphysema score. In the normal subjects the mean weight of the free right ventricular wall was $54 \mathrm{~g}$. (range 34 to $80 \mathrm{~g}$.) and in the asthma cases it was $61 \mathrm{~g}$. (range 44 to $75 \mathrm{~g}$.). The mean in the chronic bronchitis

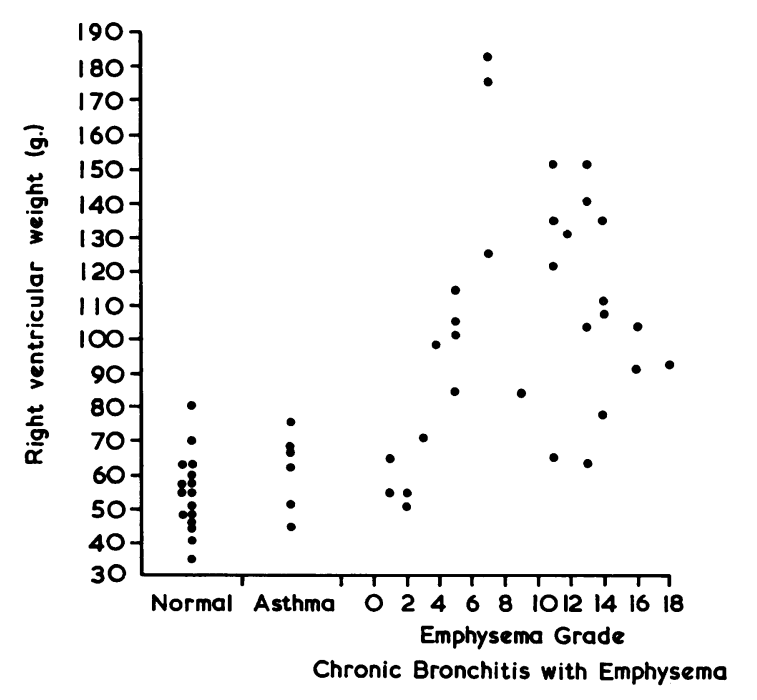

FIG. 5.-The right ventricular weights in 16 normal subjects, 6 asthmatics, and 31 patients who had had chronic bronchitis with emphysema. 
with emphysema group was $102 \mathrm{~g}$. with a wide range of 32 to $182 \mathrm{~g}$.

The emphysema score and right ventricular weight were not closely related, as is clear from Fig. 5. The ventricle was hypertrophied in 5 out of 10 cases with emphysema scores less than $6 / 18$. In 3 of the 12 with emphysema exceeding $12 / 18$ the right ventricle was normal.

This lack of relation is illustrated by Fig. 3 and 4. Fig. 3 shows a lung in which the emphysema score was 11 , the right ventricle weighing $120 \mathrm{~g}$. In contrast the lung shown in Fig. 4 had an emphysema score of 14, but the right ventricular weight was only $32 \mathrm{~g}$.

\section{Discussion}

The vessels and bronchi of the right lung were perfused with fixative for patency testing and for preparing a whole lung section. The left lung was not similarly perfused because it was needed for bacteriological examination and studies of unperfused bronchioli. In each emphysema case the lesion was symmetrical, and it is likely that any vascular change in the left lung would be similar to that in the right.

Decomposition of the lung invalidates the technique. Fluid flows very rapidly into the pulmonary artery of any decomposed lung, due to leakage into the air-spaces. This causes obvious local swelling of the lung and failure of fluid to gush from the pulmonary vein. This fallacy was avoided by restricting the test to lungs from bodies which had been dead less than 24 hours, or which were placed in a refrigerator within a few hours of death. Under these circumstances the flow times of normal lungs occupied a small range not related to the exact time elapsing after death. In the emphysema group the flow time was independent of the number of hours since death. In the absence of decomposition the flow time is repeatable with successive litres of fluid for up to about 15 minutes, the flow rate remaining constant. After about 15 minutes the rate of flow gradually becomes slower, probably due to fixation of the tissues with consequent vascular induration and shrinkage.

The temperature of the stock perfusing fixative fluid varied from $13^{\circ} \mathrm{C}$. to $16^{\circ} \mathrm{C}$. Over this temperature range the change of viscosity of dilute aqueous solutions is very small. Consequently no attempt was made to correct for small differences in perfusant temperature from case to case.

James and Thomas (1963) observed that some of the small arteries of emphysematous lungs were thick-walled and suggested that these lesions might cause permanent slight pulmonary hypertension. Thick-walled arterioles were found in all the emphysematous lungs in the present series, but in 9 of the 31 the flow rate was normal in spite of the arteriolar thickening. This suggests that restriction of vascular patency by capillary loss and arteriolar thickening can be compensated by enlargement of other channels. Reid and Heard (1963) have shown that in emphysematous lungs there are some widely patent vessels. Similarly Jacobson et al. (1965) showed, by arteriography during life, that emphysematous lungs contained arteriovenous channels of about $50 \mu$ internal diameter. One lung in the present series was of particular interest in this respect. Its emphysema score was $18 / 18$, there appearing to be an almost total loss of alveolar tissue, and some of the arterioles were thick-walled, but one litre of fluid passed through in only $25 \mathrm{sec}$.

Wood (1959) refers to a 2.5 to 5 -fold increase of resistance during life as "slight", while Harris and Heath (1962a) mention that in some patients with severe pulmonary hypertension the resistance may be increased 20-fold. By such standards the increase of resistance observed in the emphysematous lungs of the present series is certainly slight.

If vascular bed obliteration were an important cause of right ventricular hypertrophy in emphysema, a positive correlation between flow time and right ventricular weight would be expected. Rossier (1961) states that resection of two-thirds of the vascular bed causes hypertension at rest. In the present study the flow time exceeded thrice the normal maximum in 6 cases and in 5 of the 6 the right ventricle was hypertrophied. It is suggested that the measured increase of resistance would cause increase of right ventricular work, thus contributing to right ventricular enlargement. In 5 other cases the right ventricles were hypertrophied but the flow times were normal. In such instances functional factors must be invoked to explain the enlargement of the right ventricle.

This work suggests that in emphysema organic vascular bed stenosis or loss can contribute to right ventricular enlargement, but it is not an essential factor since ventricular hypertrophy can occur with a fully patent pulmonary vascular bed.

\section{SUMMARY}

This paper reports an attempt to measure the patency of the pulmonary vascular bed in lungs affected by chronic bronchitis and emphysema, the investigation being carried out on 31 lungs at necropsy. The results were compared with patency measurements in 16 normal lungs and 6 lungs from patients who had had spasmodic asthma. Vascular bed patency was assessed by timing the flow of one litre of fluid through the pulmonary 
vascular bed. In chronic bronchitis with emphysema there was a wide range of flow times but the mean flow time was three times the mean of the times for the normal lungs. There was no consistent relation between the flow times and the weights of the right ventricles, suggesting that in right ventricular hypertrophy the important ætiological factors are functional rather than organic.

I am indebted to Professor J. Gough for his stimulating interest. Mr. J. Wentworth prepared the whole lung sections, Mr. P. Stinchcombe made the photographs, and Miss E. Cronin typed the manuscript.

\section{REFERENCES}

Blount, S. G. (1959). Cardiac output in pulmonary emphysema. In Pulmonary Circulation, ed. W. R. Adams and I. Veith, p. 160. Grune and Stratton, New York and London.

Gough, J., and Wentworth, J. E. (1960). Technique of large lung sections. In Recent Advances in Pathology, 7th edn., ed. C. V. Harrison, p. 80. J. and A. Churchill, London.

Harris, P., and Heath, D. (1962a). The Human Pulmonary Circulation, p. 101. E. and S. Livingstone, Edinburgh and London.

- and - (1962b). The Human Pulmonary Circulation, p. 279. E. and S. Livingstone, Edinburgh and London.
Heard, B. E., and Izukawa, T. (1964). Pulmonary emphysema in fifty consecutive male necropsies in London. 7. Path. Bact., 88, 423.

Hugh-Jones, P. (1960) Chronic pulmonary disease. In Clinical Disorders of the Pulmonary Circulation, ed. R. Daley, J. F. Goodwin, and R. E. Steiner, p. 311. J. and $A$. Churchill, London.

Jacobson, G., Turner, A. F., Balchum, O., and Judge, C. (1965). Pulmonary arteriovenous shunts in emphysema demonstrated by wedge arteriography. Amer. $\mathcal{F}$. Roentgenol., 93, 868.

James, W. R. L., and Thomas, A. J. (1963). Right ventricular hypertrophy and the small pulmonary arteries in chronic lung disease. Brit. Heart f., 25, 583.

Leopold, J. G., and Gough, J. (1957). The centrilobular form of hypertrophic emphysema and its relation to chronic bronchitis. Thorax, 12, 219.

Reid, A., and Heard, B. E. (1963). Preliminary studies of human capillaries by India ink injection. In Normal and Abnormal Pulmonary Circulation. Fifth Annual Conference on Research in Emphysema. Aspen, Colorado, 1962, ed. R. F. Grover, p. 23. S. Karger, Basel and New York.

Rossier, P. H. (1961). The functional aspect of pulmonary hypertension. In Problems of Pulmonary Circulation. Ciba Foundation Study Group, No. 8, ed. A. V. S. de Reuck and M. O'Connor, p. 38. Churchill, London.

Wood, P. (1959). The vasoconstrictive factor in pulmonary hypertension. In Pulmonary Circulation, ed. W. R. Adams and I. Veith, p. 294. Grune and Stratton, New York and London. 